\title{
Perfil de ácidos graxos do leite de cabras leiteiras alimentadas com dieta contendo dois níveis de óleo de arroz
}

\author{
[Production and milk composition of dairy goats receiving two levels of rice \\ bran oil in the diet] \\ M.S. Vilanova ${ }^{1}$, M.T.M. Osório ${ }^{2}$, V. Schmidt ${ }^{4}$, J.C.S. Osório ${ }^{1}$, D.S. Vilanova ${ }^{3}$, J.D. Kessler ${ }^{1}$ \\ ${ }^{1}$ Programa de pós-graduação - FAEM - Universidade Federal de Pelotas - Pelotas, RS \\ ${ }^{2}$ Universidade Federal de Pelotas, Bolsistas de Produtividade do CNPq. PVNS da CAPES/UFGD \\ ${ }^{3}$ Universidade Federal de Pelotas - Graduação em Agronomia \\ ${ }^{4}$ Universidade Federal do Rio Grande do Sul - UFRGS - Porto Alegre, RS
}

\begin{abstract}
RESUMO
Foram testados os efeitos de dois níveis de extrato etéreo à base de óleo de arroz no concentrado em 30 cabras Saanen durante a fase inicial de lactação. A alimentação baseou-se na relação $60 \%$ de volumoso (feno de alfafa) e $40 \%$ de concentrado comercial com dois níveis de extrato etéreo (3\% e $5 \%$ ). As variáveis estudadas foram a quantificação e qualificação do perfil de ácidos graxos do leite total e frente ao tempo de lactação. $\mathrm{O}$ acréscimo de óleo de arroz na dieta diminuiu $(\mathrm{P}<0,05)$ a concentração de ácidos graxos saturados e aumentou $(\mathrm{P}<0,05)$ a concentração de ácidos graxos poli-insaturados no leite caprino. $\mathrm{O}$ ácido linoleico conjugado (ALC) também é afetado positivamente pelo acréscimo de óleo de arroz na dieta. A inclusão de óleo de arroz nos níveis de 3\% e 5\% da matéria seca, na dieta de cabras leiteiras da raça Saanen, influencia o perfil de ácidos graxos do leite, com ênfase no ALC, até a $11^{a}$ semana de lactação.
\end{abstract}

Palavras-chave: caprino, ácido linoleico conjugado, lactação, lipídeos

\begin{abstract}
The effects of two levels of ether extract based on rice oil concentrate in 30 Saanen goats during early lactation were evaluated. The feeding was based on the ratio of $60 \%$ forage (alfalfa hay) and $40 \%$ commercial concentrate with two levels of lipids (3\% and 5\%). The variables were the quantification and qualification of the fatty acid profile of whole milk and forward to the time of lactation. The addition of rice bran oil in the diet decreased significantly $(P<0.05)$ the concentration of saturated fatty acids and increased $(P<0.05)$ the concentration of polyunsaturated fatty acids in goats' milk. The linoleic acid was also positively affected by the addition of rice bran oil in the diet. The inclusion of rice bran oil at levels of 3\% and 5\% of dry matter in the diet of Saanen dairy goats influences the fatty acid profile of milk, with emphasis on linoleic acid until the 11th week of lactation.
\end{abstract}

Keywords: dairy goat, conjugated linoleic acid; lactation, lipid

\section{INTRODUÇÃO}

O leite caprino possui diversas peculiaridades funcionais quando incluído na alimentação humana, com uma composição de ácidos graxos de cadeia curta que se sobressai ao leite de outras espécies. Os ácidos graxos mais importantes do ponto de vista quantitativo no leite de caprinos são o palmítico (C16:0), o esteárico (C18:0) e o cáprico (C10:0). Em termos de ácidos graxos monoinsaturados (AGMI), o mais abundante é o oleico. E quanto aos poli-insaturados, destacamse principalmente os ácidos graxos linoleico, linolênico e, em menor proporção, o araquidônico (Sotillo e Méndez, 1994).

Recebido em 27 de março de 2011

Aceito em 28 de agosto de 2012

E-mail: marcele.vet@gmail.com 
Os lipídios têm sido utilizados na dieta de ruminantes como forma de aumentar a densidade energética, sem, no entanto, alterar a relação volumoso:concentrado. Previnem desordens metabólicas e melhoram o desempenho na lactação e na reprodução, e restauram, ainda, a condição corporal (Church, 1988), além de alterar a composição da gordura do leite (Chilliard, 2003). O atual enfoque do mercado sobre os produtos de origem animal tem sido direcionado à busca por alimentos com menores teores de gordura (Silva et al., 2006) e com a composição da gordura mais benéfica à saúde humana, caracterizando-os como alimentos funcionais.

O ácido linoleico conjugado (ALC) tem sido estudado amplamente, uma vez que, além de apresentar comprovadamente propriedades antimutagênicas e anticarcinogênicas, atua na redução de agentes citotóxicos existentes nas células cancerígenas (Parodi, 1999). De modo geral, a concentração de ALC na gordura do leite é dependente da presença de ácidos graxos insaturados na dieta (Griinari et al., 1998).

Desse modo, o objetivo deste trabalho foi avaliar os efeitos de dois níveis de óleo de arroz, adicionados à dieta de cabras Saanen em lactação, no perfil de ácidos graxos do leite durante as 11 primeiras semanas de lactação.

\section{MATERIAL E MÉTODOS}

O experimento foi realizado em um capril, no município de Santo Antônio da Patrulha, RS. Foram utilizadas 30 cabras da raça Saanen, de terceira e quarta ordem de lactação, com peso corporal médio de $50 \mathrm{~kg}$. As coletas compreenderam o período de outubro a dezembro de 2007, durante as 11 primeiras semanas de lactação das fêmeas.

Foram estudados os efeitos de dois níveis de extrato etéreo, à base de óleo de arroz: T3: nível de $3 \%$ na MS (matéria seca) e T5: nível de 5\% na MS. As dietas foram formuladas com base nas necessidades fisiológicas de cabras durante a fase inicial de lactação com produção média de 2,5 litros de leite em 24 horas de secreção e percentual de gordura no leite de 3,5, segundo as recomendações do NRC (National..., 1981). Foi utilizada alimentação volumosa constituída de alfafa (Medicago sativa) na forma de feno, sendo as misturas concentradas oferecidas separadamente do volumoso, duas vezes ao dia, também após cada ordenha, obedecendo à proporção volumoso:concentrado 60:40. A participação quantitativa dos ingredientes e a composição bromatológica das dietas são apresentadas na Tab. 1.

Tabela 1. Participação quantitativa dos ingredientes e a composição bromatológica das dietas experimentais

\begin{tabular}{|c|c|c|}
\hline Alimento & Tratamento $3(3 \%)-$ & Tratamento $5(5 \%)$ - \\
\hline Feno alfafa & 60,00 & 60,00 \\
\hline Concentrado $3 \%$ & 38,00 & 0,00 \\
\hline Concentrado $5 \%$ & 0,00 & 38,00 \\
\hline Suplemento Vitamínico-Mineral ${ }^{1}$ & 1,00 & 1,00 \\
\hline Sal comum & 1,00 & 1,00 \\
\hline Matéria Seca $(\%)$ & 87,44 & 87,88 \\
\hline Proteína Bruta (\%MS) & 25,82 & 25,05 \\
\hline Extrato Etéreo (\%MS) & 3,20 & 4,10 \\
\hline FDN (\%MS) & 41,54 & 40,01 \\
\hline FDA (\%MS) & 19,13 & 17,84 \\
\hline Cinzas & 11,17 & 12,02 \\
\hline
\end{tabular}

${ }^{\text {I} V}$ it. A: 135.000,00U.I.; vit. D3: 68.000,00U.I.; vit. E: 450,00U.I.; cálcio: 240,00g; fósforo: 71,00g; potássio: 28,20g; enxofre: 20,00g; magnésio: 20,00g; cobre: 400,00mg; cobalto: 30,00mg; cromo: 10,00mg; ferro: 250,00mg; iodo: 40,00mg; manganês: 1.350,00mg; selênio: 15,00mg; zinco: 1.700,00mg; flúor (máx.): 710,00mg.

As cabras foram ordenhadas manualmente duas vezes ao dia, às $7 \mathrm{~h}$ e $19 \mathrm{~h}$, sendo as amostras coletadas da mistura da produção das 15 cabras de cada grupo. O delineamento experimental utilizado foi o completamente ao acaso, com dois tratamentos. Os resultados foram submetidos à análise de variância com regressão pelo 
procedimento GLM do programa estatístico SAS (Statistical..., 2001).

\section{RESULTADOS E DISCUSSÃO}

Os níveis percentuais dos ácidos graxos butírico (C4:0), caproico (C6:0) e caprílico (C8:0) no leite não foram influenciados pelo acréscimo de óleo de arroz na dieta de cabras Saanen até a $10^{\mathrm{a}}$ semana de lactação, ficando os níveis médios gerais de $0,31 \%, 0,86 \%$ e $1,38 \%$, respectivamente.

Para Sotillo e Méndez (1994), há grande variação nos percentuais desses ácidos graxos no leite de cabras, podendo considerar amplitudes de 0,7 a 4,5\% para o ácido butírico; 1,5 a 3,3\% para o ácido caprólico e 1,9 a 3,4\% para o ácido caprílico, sendo todos os valores mínimos das amplitudes superiores aos encontrados neste estudo.

Maia et al. (2006), ao avaliarem o efeito da inclusão de diferentes fontes de óleos (sem adição de fonte de óleo; adição de $5,1 \%$ de óleo de arroz na dieta total; adição de $5,1 \%$ de óleo de canola na dieta total; adição de 5,1\% de óleo de soja na dieta total) na composição do leite de cabras Saanen, também não encontraram alteração na concentração do ácido butírico (C4:0) com a inclusão de óleos à dieta e não diferiu entre óleos estudados; entretanto, observaram redução $(\mathrm{P}<0,09)$ nas concentrações dos ácidos caproico e caprílico com a inclusão de óleos vegetais à dieta, diferindo deste experimento. Ainda segundo esses autores, para o tratamento com óleo de arroz, as concentrações foram $0,77 \%$ (butírico), 1,1\% (capróico) e 1,6\% (caprólico), valores estes mais alto que os encontrados neste trabalho.

Segundo Sotillo e Méndez (1994), os ácidos graxos mais importantes do ponto de vista quantitativo no leite de cabra são o palmítico, o esteárico e o cáprico. Com relação a esses três ácidos graxos, o acréscimo de óleo de arroz na dieta de cabras Saanen resultou em diminuição significativa $(\mathrm{P}<0001)$ nas concentrações percentuais dos ácidos palmítico (T3: 26,87 $\pm 1,60$; T5: 24,76 $\pm 1,03$ ) e cáprico (T3: $5,90 \pm 1,32$ e T5: 4,82 $\pm 0,68)$, porém não influenciou na concentração do ácido esteárico (geral: 19,52 $\pm 1,67$ ).
Para Maia et al. (2006), a inclusão de óleos vegetais na dieta promoveu aumento $(\mathrm{P}<0,01)$ da concentração do ácido esteárico na gordura do leite de cabras, que passou de $10,3 \%$ no tratamento controle para 19,7, 16,7 e 17,5\% nos tratamentos com óleo de canola, arroz e soja, respectivamente. Foi um aumento de $74 \%$ quando comparado ao tratamento controle, sem haver diferenças entre óleos de oleaginosas (canola e soja) e de arroz, nem entre as duas oleaginosas $(\mathrm{P}>0,10)$.

Com relação à concentração de ácido palmítico no leite das cabras, Maia et al. (2006) encontraram valor semelhante ao deste experimento, de 24,5\%, com a suplementação com óleo de arroz. Fernandes et al. (2008) observaram uma maior concentração de cáprico, quando fornecida uma dieta sem a adição de óleo, com um valor bem superior ao encontrado por este estudo $(10,37 \%)$.

Neste trabalho os ácidos graxos de cadeia curta do leite caprino, láurico, cáprico, mirístico e palmítico, diminuíram significativamente $(\mathrm{P}<0,05)$ com o acréscimo de óleo de arroz na dieta, ficando os valores do tratamento $3 \mathrm{em}: 3,1$, $5,9,8,6$ e $26,9 \%$ e os valores do tratamento $5 \mathrm{em}$ $2,4, \quad 4,8, \quad 7,1$ e $24,8 \%$, respectivamente. Resultados semelhantes foram encontrados por Fernandes et al. (2008), que encontraram aumento $(\mathrm{P}<0,05)$ nas concentrações dos ácidos graxos de cadeia curta, quando fornecida dieta sem adição de óleo, o que parece ser um indício de maior participação dos ácidos graxos de cadeia longa provenientes dos óleos utilizados.

A redução da proporção dos ácidos graxos de cadeias curta e média pode ser decorrente da diminuição de precursores da síntese de novo, acetato e $\beta$-hidroxibutirato, resultantes da fermentação ruminal, ou da direta inibição do complexo enzimático envolvido na síntese de novo pela ação dos ácidos graxos de cadeia longa dos óleos vegetais (Palmquist et al., 1993). Para a justificativa dos resultados deste experimento, a segunda opção é a mais possível, uma vez que os níveis de percentuais de gordura não foram influenciados pelo tratamento, sugerindo não ter havido dano à produção do acetato em nível ruminal, pois, quando a capacidade dos microrganismos em saturar os ácidos graxos for ultrapassada, os ácidos graxos insaturados 
acumulam-se e interferem na fermentação ruminal (NRC, 2001).

Decréscimo na concentração dos ácidos graxos de cadeia curta, principalmente o mirístico, torna-se positivo do ponto de vista da saúde humana, uma vez que excessos nas concentrações desses ácidos na alimentação podem proporcionar sérios problemas à saúde (Fuentes, 1998).
Com relação aos ácidos graxos monoinsaturados, o acréscimo de óleo de arroz na dieta de cabras Saanen teve efeito significativo (Tab. 2) apenas sobre o ácido graxo oleico (18:1n-9), o qual, em termos de ácido graxo monoinsaturado do leite de cabra, é o mais abundante (Sotillo e Méndez, 1994).

Tabela 2. Médias e erros padrão do perfil de ácidos graxos monoinsaturados da gordura do leite de cabras Saanen, em g/100g de lipídios, alimentadas com dois níveis de óleo de arroz (3\% e 5\%), durante as 10 primeiras semanas de lactação

\begin{tabular}{lllll}
\hline Ácidos Graxos & Tratamento 3 (3\%) & Tratamento 5 (5\%) & Média & Pr>F \\
\hline C14:1 Miristoleico & $0,18 \pm 0,18$ & $0,11 \pm 0,15$ & $0,15 \pm 0,18$ & 0,75 \\
C16:1 Palmitoleico & $0,39 \pm 0,06$ & $0,43 \pm 0,06$ & $0,41 \pm 0,05$ & 0,14 \\
C17:1 8-heptadecanoico & $0,10 \pm 0,11$ & $0,13 \pm 0,1$ & $0,11 \pm 0,05$ & 0,22 \\
C18:1 trans -11 Vacênico & $1,29 \pm 1,18$ & $3,29 \pm 1,29$ & $2,29 \pm 1,07$ & 0,06 \\
C18:1n 9c Oleico & $23,86 \pm 2,97$ & $25,79 \pm 2,4$ & $24,83 \pm 1,06$ & 0,04 \\
C18:1n 9t elaídico & $1,55 \pm 1,28$ & $1,07 \pm 1,5$ & $1,31 \pm 1,02$ & 0,35 \\
C20:1 11- eicosenoico & $0,09 \pm 0,004$ & $0,10 \pm 0,006$ & $0,09 \pm 0,01$ & 0,54 \\
AGMI & $24,55 \pm 3,05$ & $26,56 \pm 2,34$ & $25,56 \pm 1,09$ & 0,14 \\
\hline
\end{tabular}

AGM: ácidos graxos monoinsaturados.

O ácido oleico apresentou um aumento significativo influenciado pelo maior nível de óleo de arroz na dieta, concordando com Fernandes et al. (2008), que também observaram maiores concentrações deste $(\mathrm{P}<0,05)$ com a inclusão dos óleos, assim como a elevação na concentração de insaturados depositados no leite $(\mathrm{P}<0,05)$. Maia et al. (2006) observaram que a inclusão de óleos vegetais na dieta elevou $(\mathrm{P}<0,01)$ a concentração do ácido oleico (18:1n-9), de modo que o valor encontrado
$(35,2 \%)$ foi $37 \%$ superior ao obtido com a dieta controle $(25,67 \%)$.

Com relação aos ácidos graxos poli-insaturados, observou-se (Tab. 3) que, dos identificados no leite de cabras Saanen, o ALC (C18:2 cis 9, trans 11) e o $\mathrm{C} 18: 3 n 3$ foram os únicos que sofreram influência significativa com acréscimo de óleo na dieta $(\mathrm{P}<0,05)$. Em termos de ácidos graxos poliinsaturados, os que se destacam em caprinos são o linoleico, linolênico e, em menor proporção, o araquidônico (Sotillo e Méndez, 1994).

Tabela 3. Médias e erros padrão do perfil de ácidos graxos poli-insaturados e ácido linoleico conjugado (ALC) da gordura do leite de cabras Saanen, em g/100g de lipídios, alimentadas com dois níveis de óleo de arroz (3\% e 5\%), durante as 10 primeiras semanas de lactação

\begin{tabular}{lllll}
\hline Ácido graxo & Tratamento 3 $(3 \%)$ & Tratamento 5 (5\%) & Média & Pr>F \\
\hline C18:2n 6c Linoleico & $3,20 \pm 0,21$ & $3,28 \pm 0,21$ & $3,24 \pm 0,19$ & 0,21 \\
C18:3n6 Linolênico & $0,04 \pm 0,02$ & $0,04 \pm 0,05$ & $0,04 \pm 0,03$ & 0,16 \\
C18:2 cis 9, trans 11 ALC & $0,37 \pm 0,19$ & $0,72 \pm 0,009$ & $0,47 \pm 0,24$ & 0,05 \\
C18:3n3 & $0,80 \pm 0,15$ & $0,69 \pm 0,20$ & $0,75 \pm 0,14$ & 0,005 \\
C20:4n 6 Araquidônico & $0,19 \pm 0,25$ & $0,19 \pm 0,03$ & $0,19 \pm 0,02$ & 0,11 \\
AGPI & $4,19 \pm 0,33$ & $4,28 \pm 0,44$ & $4,23 \pm 0,28$ & 0,02 \\
\hline
\end{tabular}

AGPI: Ácidos graxos poli-insaturados. 
Ainda segundo os mesmos autores, as concentrações desses ácidos graxos, para o leite de cabra, pode variar de 0,5 a 3,8\% (linoleico) e de 0,2 a 4,1\% (linolênico). Para Fernandes et al. (2008), as concentrações dos ácidos esteárico (C18:0), oleico (C18:1) e linoleico (C18:2) aumentaram $(\mathrm{P}<0,05)$ com a inclusão dos óleos, bem como a quantidade de insaturados depositados no leite também se elevou $(\mathrm{P}<0,05)$. Com relação ao ácido linoleico conjugado (ALC), o acréscimo de óleo de arroz afetou significativamente $(\mathrm{P}<0,05)$ sua concentração no leite de cabras Saanen, chegando a um aumento (T5) de quase $100 \%$ comparado ao T3.

Maia et al. (2006) encontraram aumento de 55\% na concentração de ALC na gordura do leite de cabras, comparando a dieta controle às de inclusão de óleo vegetal, obtendo médias de 0,$91 ; 1,1 ; 1,4$ e $1,7 \%$ para os tratamentos controle, óleo de canola, arroz e soja, respectivamente, todas acima dos encontrados neste estudo. Mir et al. (1999), ao estudarem os efeitos da adição de níveis crescentes de óleo de canola na dieta de cabras em lactação, verificaram que o percentual de ALC passou de 88 para $210 \%$ quando a inclusão de óleo passou de 2 para $4 \%$, respectivamente, em relação ao tratamento sem óleo. Contudo, não encontraram efeito benéfico no aumento do conteúdo de ALC com a inclusão de $6 \%$ de óleo de canola. O aumento obtido na concentração de ALC no leite torna esse alimento com características mais apreciadas e benéficas à saúde humana, o que gera uma possibilidade ao produtor de agregação de valor na venda e de diminuição dos custos com o acréscimo de óleo na dieta.

Segundo Gulati et al. (1997), a quantidade de ácidos graxos transferidos da dieta para a gordura do leite está diretamente relacionada ao nível de proteção implementado à fonte suplementar de óleo e ao tipo de suplemento empregado. Portanto, a manipulação da dieta de cabras leiteiras, dependendo do objetivo proposto para o produto final, pode ser uma forma de controlar as características nutricionais e/ou físico-químicas da gordura do leite.

Entre os ácidos graxos, observam-se comportamentos diferentes, com relação às doenças cardiovasculares, acreditando-se que os ácidos palmítico (C16:0) e mirístico (C14:0) elevam os níveis de lipoproteínas de baixa densidade (LDL-colesterol) em maior proporção que o ácido esteárico (C18:0), e que o ácido láurico (C12:0) promove hipercolesterolemia, sendo em menor quantidade que os ácidos palmítico (C16:0) e mirístico (C14:0). Acreditase, ainda, que os ácidos graxos monoinsaturados, como, por exemplo, o ácido oleico, não influem nos níveis de colesterol. Com relação ao ácido elaídico (C18:1), resultante dos processos de hidrogenação de óleos vegetais, existem indícios de que poderia induzir à hipercolesterolemia. Por sua vez, os poli-insaturados, como o ácido linoleico (C18:2), reduzem os níveis séricos de LDL-colesterol (Fuentes, 1998).

Mesmo com variações significativas em alguns ácidos graxos e não em outros, o acréscimo de óleo de arroz na dieta de cabras Saanen diminuiu significativamente $(\mathrm{P}<0,05)$ a concentração total de ácidos graxos saturados (de $68,7 \%$ para $64,5 \%)$ e aumentou $(\mathrm{P}<0,05)$ a de ácidos graxos poli-insaturados (de $4,2 \%$ para $4,3 \%$ ), podendo ser justificada pelo bom nível de insaturação dos ácidos graxos que compõem o óleo de arroz.

Para Maia et al. (2006), a concentração de ácidos graxos saturados (AGS) na gordura do leite das cabras no tratamento controle foi mais alto $(\mathrm{P}<0,01)$ que a obtida com suplementação, como resultado do alto nível de insaturação das fontes de óleos vegetais utilizadas na formulação das dietas. Porém, não houve diferença entre a suplementação com óleo de arroz e óleo de oleaginosas nem entre as oleaginosas (média de $57 \%$ para esses tratamentos).

A inclusão de óleo de arroz, em nível de 5\%, na dieta de cabras Saanen, diminui em 6,8\% a concentração de AGS no leite, dados também obtidos por Maia et al. (2006), que concluíram que a inclusão de óleos vegetais ricos em ácido graxo poli-insaturado (AGPI) na dieta de cabras leiteiras reduziu em $15,6 \%$ a concentração de ácidos graxos saturados quando adicionados em nível de $5,1 \%$ da dieta. Concomitantemente à redução verificada na concentração de AGS, houve elevação $(\mathrm{P}<0,01)$ na concentração de AGPI na gordura do leite quando as dietas foram enriquecidas com fontes de óleos vegetais. Tendência semelhante foi relatada por Santos et al. (2001), em pesquisa com vacas alimentadas com dietas contendo grão e óleo de soja. 
Dados obtidos por Nydahl et al. (1994), as dietas enriquecidas com PUFAs ocasionaram diminuição de $19 \%$ na concentração do colesterol sérico total e $23 \%$ da LDL-colestrol, e as enriquecidas com MUFAs, uma diminuição de $17 \%$ e $19 \%$, respectivamente.

Embora tenha sido observada alteração na concentração de ácidos graxos frente ao período de lactação das cabras Saanen até a $11^{\mathrm{a}}$ semana pós-parto, é evidente, nesse caso, que a influência primordial na variação da composição da gordura do leite se deve, sim, ao fator nutrição.

\section{CONCLUSÃO}

Os teores de ácidos graxos saturados, poliinsaturados e do ácido linoleico conjugado são afetados pelo nível de óleo de arroz na dieta de cabras Saanen até a $11^{\mathrm{a}}$ semana de lactação.

\section{REFERÊNCIAS}

CHILLIARD, Y.; FERLAY, A.; ROUEL, J.; LAMBERET, G. A Review of Nutritional and Physiological Factors Affecting Goat Milk Lipid Synthesis and Lipolysis. J. Dairy Sci., v.86, p.1751-1770, 2003.

CHURCH, D.C. El rumiante: fisiologia digestiva y nutrición. Zaragoza, España:Acribia, 1988. $641 \mathrm{p}$.

FERNANDES，M.F.; QUEIROGA， R.C.R.E.; MEDEIROS, A.N. et al. Características físicoquímicas e perfil lipídico do leite de cabras mestiças Moxotó alimentadas com dietas suplementadas com óleo de semente de algodão ou de girassol. Rev. Bras. Zootec., v.37, p.703710, 2008

FUENTES, J.A.G. Que alimentos convêm ao coração? Higiene Alimentar, v.12, p.7-11, 1998.

GRIINARI, J.M.; DWYER, D.A.; McGUIRE, M.A. et al. Trans-octadecenoic acids and milk fat depression in lactating dairy cows. J. Dairy Sci., v.81, p.1251-1261, 1998.

GULATI, S.K.; BYERS, E.B.; BYERS, Y.G. Effect of feeding different fat supplements on the fatty acid composition of goat milk. Anim. Feed Sci. Techn., v.66, p.159-164, 1997.
MAIA, F.J.; BRANCO, A.F.; MOURO, G.F. et al. Inclusão de fontes de óleo na dieta de cabras em lactação: produção, composição e perfil dos ácidos graxos do leite. Rev. Bras. Zootec., v.35, p.1496-1503, 2006

MIR, Z.; GOONEWARDENE, L.A.; OKINE E. et al. Effect of feeding canola oil on constituents, conjugated linoleic acid (ALC) and long chain fatty acids in goats milk. Small Rumin. Res., v.33, p.137-143, 1999.

NATIONAL Research Council - NRC. Nutrient requirements of dairy cattle. 7.ed. Washington, DC.: National Adacemy of Sciences, 2001. 381p

NYDAHL, M.C.; GUSTAFSSON, I.B.; VESSBY, B. Lipid-lowering diets enriched with monounsaturated or polyunsaturated fatty acids but low in saturated fatty acids have similar effects on serum lipid concentrations in hyperlipidemic patients. Am. J. Clin. Nutrit., v.59, p.115-122, 1994.

PALMQUIST, D.L.; BEAULIEU, A.D.; BARBANO, D.M. Feed and animal factors influencing milk fat composition. J. Dairy Sci., v.76, p.1753-1771, 1993.

PARODI, P.W. Conjugated linoleic acid and other anticarcinogenic agents of bovine milk fat. J. Dairy Sci., v.82, p.1339-1349, 1999.

SANTOS, F.L.; SILVA, M.T.C.; LANA, R.P. et $a l$. Efeito da suplementação de lipídios na ração sobre a produção de ácido linoleico conjugado (CLA) e a composição da gordura do leite de vacas. Rev. Bras. Zootec., v.30, p.1931-1938, 2001.

SILVA, H.G.O.; PIRES, A.J.V.; SILVA, F.F. et al. Características físico-químicas e custo do leite de cabras alimentadas com farelo de cacau ou torta de dendê. Arq. Bras. Med. Vet. Zootec., v.58, p.116-123, 2006.

STATISTICAL Analysis Sistem - SAS Institute Inc. SAS Users's Guide, Statistcs, Edition Cary, v.8.2, NC, SAS INSTITUTE INC., 2001.

SOTILLO, A.Q.; MÉNDEZ, M.L.H. La leche de cabra. Murcia: Universidad, Secretariado de publicaciones, 1994. 90p. 